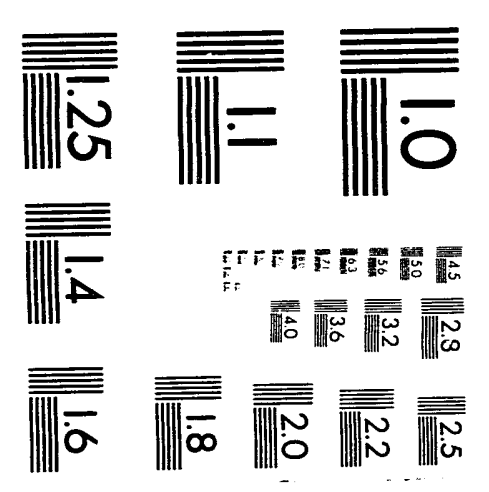



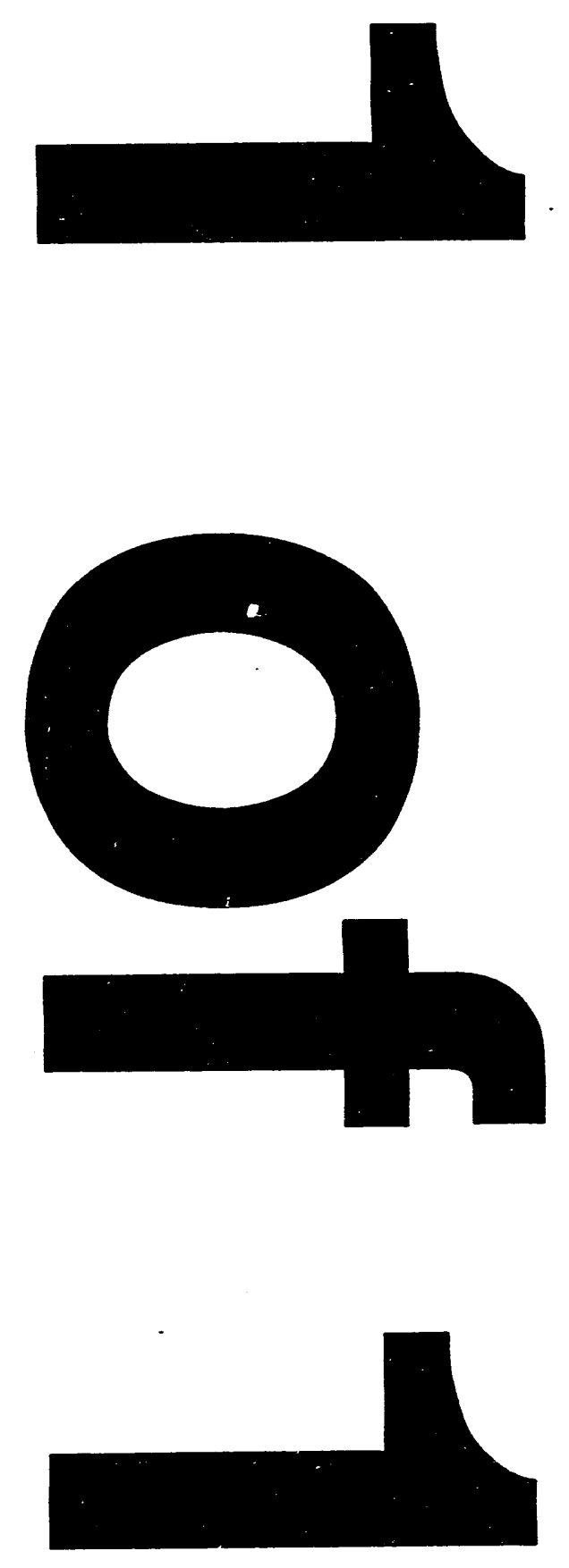


\section{Coy $9309199-8$}

UCRL-JC-112979

PREPRINT

\section{Using Laser Absorption Spectroscopy to Monitor Composition and Physical Properties of Metal Vapors}

L. V. Berzins

This paper was prepared for submittal to the SPIE - The International Society for Optical Engineering

Boston, MA

September 7-10, 1993

September 3, 1993

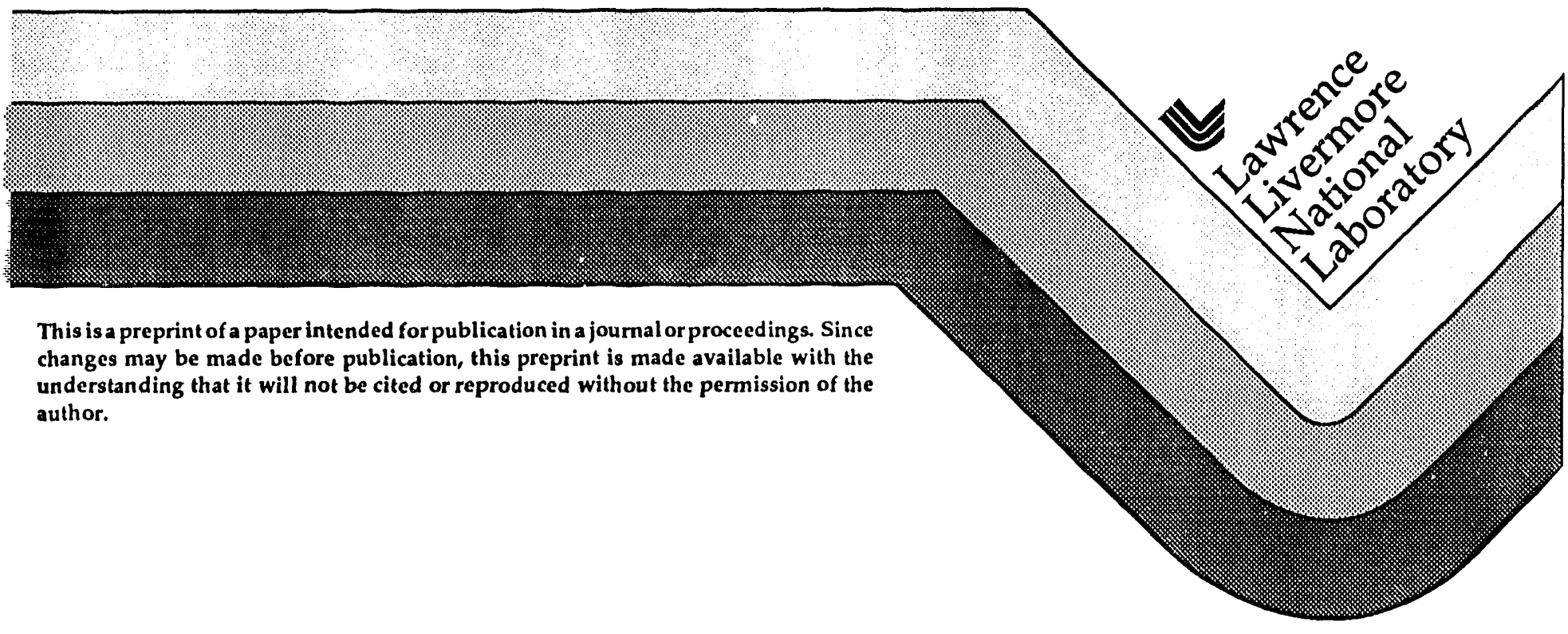




\section{DISCLAIMER}

This document was prepared as an account of work sponsored by an agency of the United States Government. Neither the United States Government nor the University of California nor any of their employees, makes any warranty, express or implied, or assumes any legal liability or responsibility for the accuracy, completeness, or usefulness of any information, apparates, product, or process disclosed, or represents that its use would not infringe privately owned rights. Reference herein to any specific commercial products, process, or service by trade name, trademark, manufacturer, or otherwise, does not necessarily constitute or imply its endorsement, recommendation, or favoring by the United States Govemment or the University of California. The views and opinions of authors expressed herein do not necessarily state or reflect those of the United States Government or the University of California, and shall not be used for advertising or product endorsement purposes. 


\title{
Using laser absorption spectroscopy to monitor composition and physical properties of metal vapors*
}

Leon V. Berzins

Lawrence Livermore National Laboratory

P.O. Box 808, L-470, Livermore, California 94550

\begin{abstract}
The Atomic Vapor Laser Isotope Separation (AVLIS) program has been using laser absorption spectroscopy to monitor vapor densities for over 15 years. Laser absorption spectroscopy has proven itself to be an accurate and reliable method to monitor both density and composition. During this time the diagnostic has moved from a research tool toward a robust component of a process control system. The hardware used for this diagnostic is discussed elsewhere at this symposium.1,2 This paper describes how the laser absorption spectroscopy diagnostic is used as a component of a process control system as well as supplying detailed measurements on vapor densities, composition, flow velocity, internal and kinetic temperatures, and constituent distributions. Examples will be drawn from the uranium AVLIS program. In addition potential applications such as composition control in the production of metal matrix composites or aircraft alloys will be discussed.
\end{abstract}

\section{INTRODUCTION}

Laser absorption spectroscopy (LAS) has been a useful tool in an experimental environment for many years. In this paper we describe a LAS system implemented for production process control and the variety of information that can be obtained from such a system. LAS has distinct advantages for process monitoring and control. LAS provides a non-intrusive measure of the vaporization rate as well as the vapor composition. A line of sight through the vapor plume in a well defined geometry is required, however, all the hardware is external to the vacuum chamber, insuring reliability and maintainability. In addition, LAS requires no hardware calibration. The laser is swept in frequency through the absorption line of interest in order to obtain a baseline. The amount of light absorbed is therefore referenced to a measured baseline. Thus density can be calculated as long as lixe atomic transition strength is known. Another advantage of LAS is that it supplies good sensitivity for a wide range of elements and densities. Careful selection of the measurement geometry in combination with the atomic transition allows excellent flexibility in meeting sensitivity requirements. Finally, LAS has very good specificity. LAS is element specific and in sume cases even isotope specific. Proper choice of the absorption line insures that the only element being measured is the element of interest.

Laser absorption spectroscopy has been successfully applied to controlling both composition and vaporization rates for various systems in the Atomic Vapor Laser Isotope Separation Program (AVLIS). The AVLIS Program represents the next generation technology for selcctively enriching one isotope relative to the natural concentration. This process was developed for enriching uranium to be used as fucl for nuclear power plants. This process has also been examined as a method for enriching isotopes of gadolinium, mercury, oxygen and carbon. As this technology has been pushed toward commercialization, the necessity for a fast, low cost, and reliable process control system became tantamount. We have developed a LAS diagnostic which is the heart of this system. Key features of this system are incorporation of a diode laser for increased reliability and low maintenance costs, and line-locked and frequency swept operation to handle various acquisition rate requirements. This diagnostic supplies a direct measure of the constituent densities in the vapor plume. These densitics are the inputs into a vaporizer control system which controls the electron beam system and the feeder systems.

\section{AVIIS PROCESS DESCRIPTION}

The uranium AVLIS program represents the next generation technology for enriching uranium for use in nuclear power plants. In the AVLIS process, uranium is vaporized and the U235 isotope is selectively photo-ionized for subsequent electrostatic collection. This process is shown schematically in Figure 1. A high power electron beam system is used to covaporize a mixlure or uranium and iron. The cconomics of the AVLIS process are driven by the vaporization rate, the distribution of internal states of uranium, the collection efficiency, and component lifetime. Each one of these factors is 
critically dependent on the specific properties of the vapor. The vaporization rate and internal temperature are directly measurable, while the collection efficiency is dependent on the flow velocity and flow direction as well as the flux distribution. Finally, the component lifetime in a corrosive liquid uranium environment depends of the component temperature which is set by the mole fraction of the uranium-iron mixture. Thus, in order to optimize the AVLIS process, a detailed understanding of the uranium-iron vapor properties is necessary.

We have used our LAS'system to develop the necessary understanding of the uranium-iron vapor properties. With a combination of multiple laser shot locations and multiple laser wavelengths, we have simultancously measured all of the pertinent vapor propertics. Using this understanding, we have implemented a closed loop vaporizer control system. In the sections that follow, we summarize the density measurements, overview the vaporizer control system, and provide examples of additional process paramcters that can be measured using LAS. After presenting these AVLIS examples, other potential applications of this diagnostic are discussed.

\section{EXPERIMENTAL METHOD}

The vapor rate monitor has two different modes of operation; a frequency swept mode and a real-time mode. In the frequencyswept mode the lasing frequency is periodically scanned across the absorption line. Figure 2 shows a typical absorption waveform for clectron beam vaporization of gadolinium. The frequency scale is generated from the output of a $300 \mathrm{MHz}$ Fabry-Perot. The Fabry-Pcrot is run in parallel with the laser shot through the vapos plume. A notable feature of Figure 1 is the $4 \mathrm{GHz}$ full width at the half maximum (FWHM) point of the absorption profile. This data was obtained from an offline facility that uses an electron beam system that produces a spot source. In this case, the width of the absorption profile is dominated by doppler broadening. Therefore, as long as the flow velocity is much larger than the velocity perpendicular to the flow direction, the frequency spread of the absorption profile represents spatial sampling of the density distribution along the laser path. In addition, the width of the absorption waveform can also be used as an estimate of the flow velocity. For Figure 2, a flow velocity of $508 \mathrm{~m} / \mathrm{s}$ is calculated for a FWHM of $1.0 \mathrm{GHz}$ for a single isotopic component and a transition wavelength of $5676 \AA$. This flow velocity is consistent. with the anticipated pool temperature of greater than $2000 \mathrm{~K}$.

From Beer's law, $\mathrm{I} / \mathrm{I}_{0}=\mathrm{e}^{-\mathrm{n} \sigma \mathrm{d}}$, where $\mathrm{I} / \mathrm{I}_{0}$ is the fraction of transmitted light, $\mathrm{n}$ is the density, $\sigma$ is the atomic transition cross section, and $d$ is the pathlength, the line-integrated density for the state being monitored can be calculated. By monitoring two atomic states, the electronic temperature of a species in thermodynamic equilibrium can be determined. For a MaxwellBoltzmann distribution, the electronic temperature can be calculated from two clectronic state densities as follows

$$
T=-(\Delta E / k)\left\{\operatorname{In}\left(n_{1} g_{2} / n_{2} g_{1}\right)\right\}^{-1}
$$

where $T$ is the electronic or internal temperature, $\Delta \mathrm{E}$ is the energy difference between states 1 and $2, \mathrm{k}$ is Boltzmann's constant, $n_{j}$ is the density of state $i$, and $g_{i}$ is the degeneracy of statc $i$. Once the electronic temperature of a species is known, the total density of the species can be calculated by summing the contributions from each of the electronic states. The composition of the vapor is measured by monitoring several elements simultancously. This configuration has been run at acquisition rates as fast as $2 \mathrm{~Hz}$ and can easily be upgraded to operate at rates up to $10 \mathrm{~Hz}$.

The real-time configuration was developed to track density fluctuations occurring on time scales shorter than 5 seconds. In the real time configuration, the laser is locked to the center of the absorption peak. The log of the fraction of transmitted light is scaled to the total density calculated in the swept mode in a linear fashion. This scaling is periodically updated. The offset represents the bascline when there is no absorption. A multiplicative factor takes into account not only the linear scaling of density with the logarithm of the transmission, but also effects due to variations in the internal temperature and the absorption waveform. By incorporating this analysis in hardware, an essentially continuous monitor of the vapor density or composition is available.

The real-time configuration does not have the physics content of the frequency-swept mode, but this deficiency is more than compensated for by its simplicity and the availability of the fast time response. Whether the objective is to control deposition rate, vaporization rate, or vapor composition, the real-time configuration provides an ideal input to a vapor control system.

\section{VAPORIZER CONTROL SYSTEM}

In a plant there will be upwards of 100 vaporizers running simultancously on a continuous basis. An automated vaporizer control system is a critical component for achicving this goal. We describe a system based on laser absorption spectroscopy that has met the requirements of a plant environment. 
In the uranium AVLIS program, control of the vaporization rate and the vapor composition is achicved through variations in the clectron beam current and the uranium and iron feed rates. Figure 3 schematically illustrates the vaporizer control system. An internal model control methodology has becn employed. In our initial implementation a linear model was adequate for stable vaporizer control. The performanec of the vaporizer control system is illustrated in Figure 4. System performance has been optimized by filtering the input parameters to remove high frequency fluctuations and outliers thercby increasing controller robustness. In addition, the internal model control methodology allows the controller to be tuned on-line by changing only one parameter per control loop. This proved extremely useful in the development stages of the vaporizer control system, but unnecessary for subsequent runs, once the optimal control loop gains were identified. This controller meets program performance requirements but requires an operator to handle off-normal operating conditions.

Improvements in the present system will allow for tighter control bands and better handling of off-normal conditions. These improvements will come in three areas, the sensors, the model, and the actuators. Faster sampling of the sensor data coupled with a signal indicating sensor status will increase control system reliability. Adding more sophisticated models improves controller response to fluctuation and off-normal conditions. Finally, reducing actuator delay times and increasing actuator reliability reduces fluctuations and the occurrence of off-normal conditions. The addition of these features completes development of an automated vaporizcr control system.

\section{EXAMPLES}

For our process, vapor density and composition are important, but other important process parameters can also be measured with this diagnostic. A prime cxample of this is determination of the vapor distribution, a critical piece of information for turning the measured density into a vaporization or deposition ratc. Qualitative information is available in the absorption waveform. In Figure 5, the absorption waveform is smooth and symmetric, indicating a well behaved iron distribution. In Figure 6, a surplus of iron was introduced into one end of the melt causing preferential vaporization of iron from that end. The absorption waveform in that case is seen to be skewed to one side. This qualitative indicator was verified by post-run sampling of the deposited films and is now a standard indicator of nominal performance.

Quantitative measures of the distribution are also possible when the form of the distribution is known. When operating with a spot source, it is common to express the density distribution as

$$
n(r, \theta)=\left(n_{0} / r^{2}\right) \cos ^{m_{\theta}}
$$

where $\mathrm{n}$ is the density at radius, $\mathrm{r}$, and angle $\theta$ from the normal to the pool, $\mathrm{n}_{0}$ is a normalization constant representing the density at position $\left(\mathrm{r}_{0}, \theta_{0}\right)$, and $\mathrm{m}$ is a number related to the efficiency of vaporization. In low efficiency vaporization $\mathrm{m}$ is taken to be 1 , while in high efficiency vaporization $m$ is taken to be 3 . With two distinct laser shots the value of $m$ can be measured for each species in the vapor. In addition, with the density distribution measured, the absorption waveform can then be used to calculate the velocity of atoms in the vapor plume. Once the density distribution and the velocity are known, the flux distribution can be calculated. Knowledge of the flux distribution for each species allows the process to be optimized for both composition and deposition rate. Figure 7 shows the accuracy obtainable by applying this kind of methodology to the uranium AVLIS program. In Figure 7, the accuracy of the vaporization rate monitor is seen to be better than $1 \%$ when compared to the post-run weigh back on the amount of matcrial vaporized. The vapor rate diagnostic has consistently measured the total material vaporized over the history of the AVLIS Program.

Another application of LAS is to measure the response time of the vapor to changes in the source. The real-time configuration is cspecially well suited to measuring vapor response times. Figure 8 shows the iron and uranium response as a charge of pure iron is dropped into the pool. Instantaneously the iron vaporization rate increases while the uranium vaporization rate plummets. When most of the iron charge has been vaporized, the vapor composition relaxes to an iron density somewhat higher than before the charge was fed. This example, while extreme, shows the response time of the vapor plume to variations in the composition, an important parameter for the control system when vapor composition is important.

These examples represent just a few of the measurements possible with the laser absorption diagnostic. In the AVLIS Program, we have used this kind of system to measure local densities, make direct measurements of the flow velocity, the uranium charge exchange coefficient, and kinetic temperatures of the vapor in directions perpendicular and parallel to the flow direction, as well as to characterize the effect of vapor source variations on all of these parameters. The versatility of this diagnostic lends itsell to other applications where vapor phase dynamics are critical to the process. 


\section{OTHER APPLICATIONS}

In the process of developing AVLIS, we have developed expertise in melt dynamics, vapor dynamics, spectroscopy and laser technology. In addition, we have operational experience with dye and diode lasers as well as interfacing optical and optoelectronic hardware to a liquid metal environment. Our success with a diode-laser based absorption diagnostic has encouraged us to look at other potential applications for this diagnostic. One such example is the use of electron beam vaporization in the field of rapid prototyping. Various alloys are of interest, but most consist of elements with vastly different vapor pressures. For example, in 316 stainless stecl the vapor pressures of iron and molybdenum differ by more than 3 orders of magnitude at $3000 \mathrm{~K}$. In an electron beam vaporization process this difference in vapor pressures would lead to variations in the composition of the deposited alloy. These variations can be minimized by incorporating a vapor composition control system based on a diode laser absorption diagnostic.

Another potential application is process control of the plasma etching of semiconductors. At present, this process is recipe driven with the acknowledgment that some of the batches will be unacceptable. Monitoring the critical species would allow real-time decisions and/or corrections to be made. Even a modest increase in productivity would represent a significant edge in the highly competitive semiconductor industry.

These are just two specific examples where a production style laser absorption diagnostic could play a significant role. Other areas where this diagnostic could be incorporated include thin film deposition control, automobile emissions monitoring, and waste strcam monitoring.

\section{CONCLUSIONS}

Laser absorption spectroscopy has been a standard tool in the laboratory for many ycars. With the advent of diode lasers, this technology is now ready to make its way out into the production and process control environments. Our experience in the Uranium AVLIS Program demonstrates not only the reliability of such a system, but also the wealth of process data obtainable with such a system. With the continued development of diode lasers, we believe this technology will become a standard part of production process control.

\section{ACKNOWLEDGMENTS}

These measurements would not have been possible without the development work and dedicated support of the diagnostic lasers group and the CNC diagnostics group. I would also like to thank M.A. McClelland for explaining the vaporizer control system, and D.G. Braun for his help in analyzing the mountains of data we have acquired.

\section{REFERENCES}

1. "The use of laser diodes for control of uranium vaporization rates", Karla G. Hagans, Joseph J. Galkowski, Boston '93.

2. "A laser absorption spectroscopy system for L-AVLIS process monitoring and control", Joseph J. Galkowski and Karla G. Hagans, Boston '93

*This work was performed under the auspices of the U.S. Department of Energy by Lawrence Livermore National Laboratory under contract no. W-74()5-Eng-48. 


\section{AVLIS process steps}

Product and tails withdrawn as liquid in continuous process

Remaining vapor flows to roof as tails

Superimposed pulses of $\mathbf{3}$ lasers selectively photoionize vapor

Vapor generated by electron beam heating

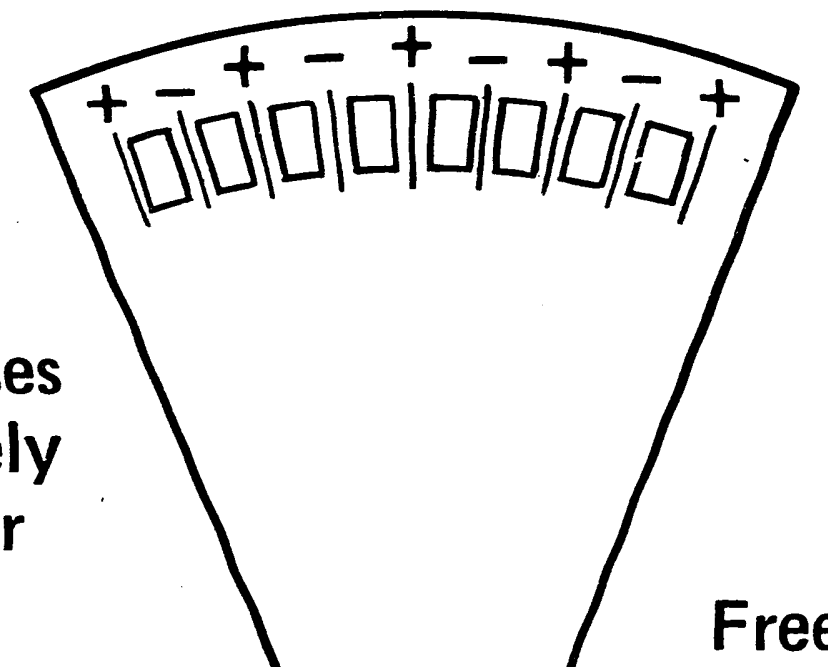

Free expansion converts vapor to cooled, hypersonic flow

FIgure 1: The atomic vapor laser isotope separation (AVLIS) process vaporizes the metal of interest with an electron beam, then selectively ionizes the Isotope of Interest for electrostatic collection. 
vrm1 . ctrad Gd D absorb_up . data

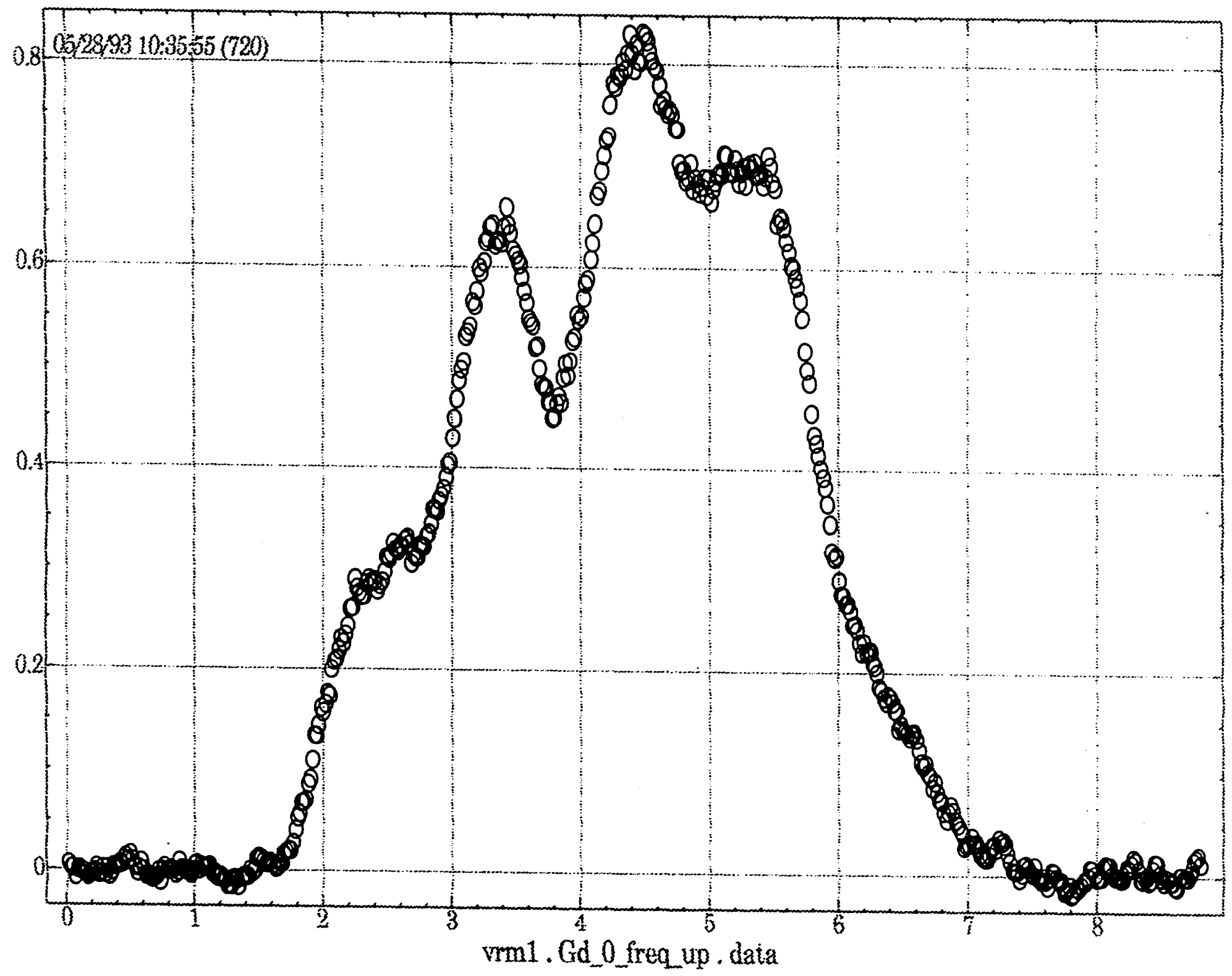

Figure 2: Sample absorption trace for vaporization of gadolinium. The multiple peaks come from the five isotopes of gadolinium. 


\section{Vaporizer control system}

MARTWMARUETRA

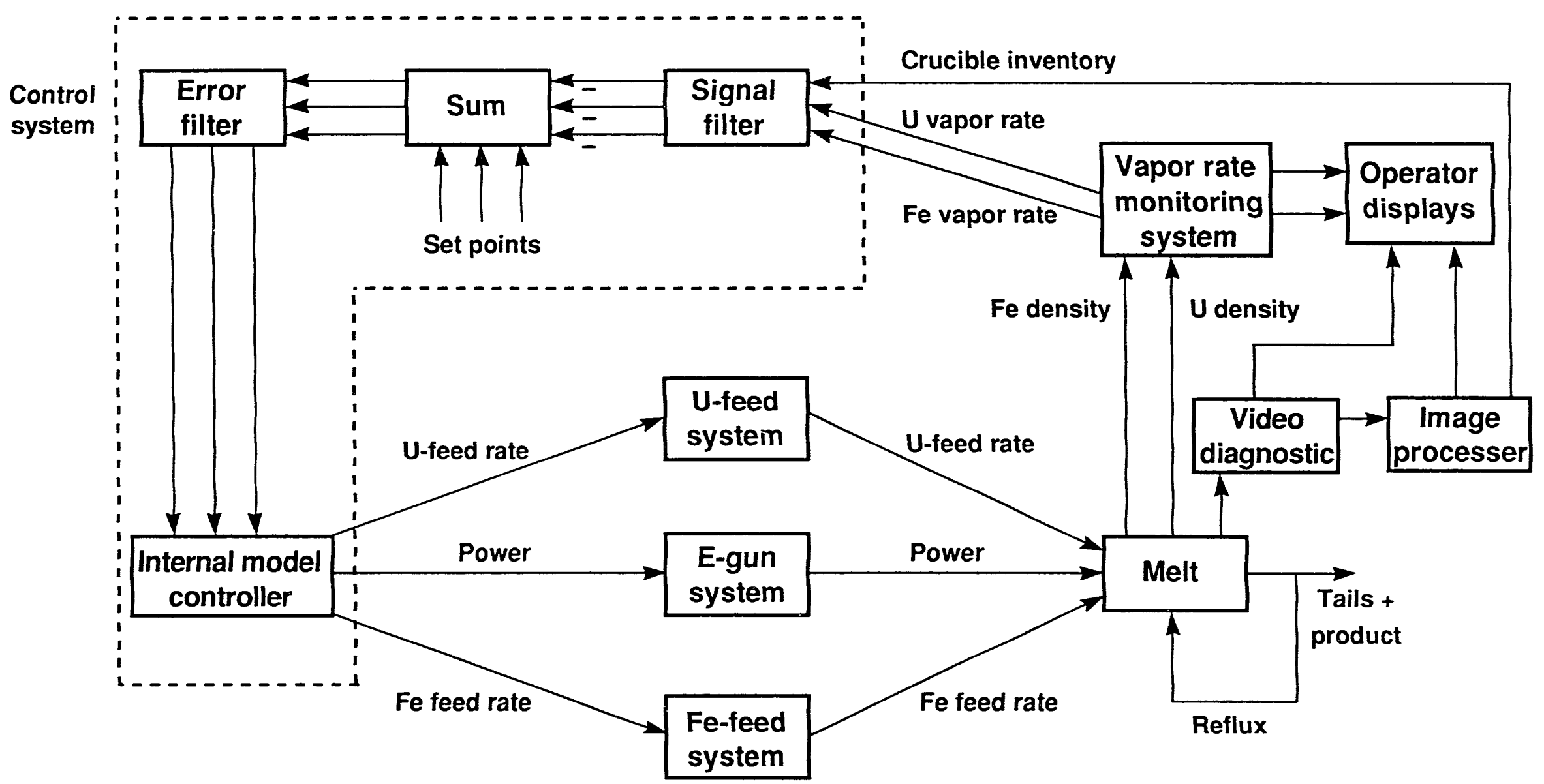

Figure 3: Schematic diagram of the vaporizer control system used in the Uranium AVLIS Program. 


\section{Model based control demonstrated in uranium enrichment demonstrations}

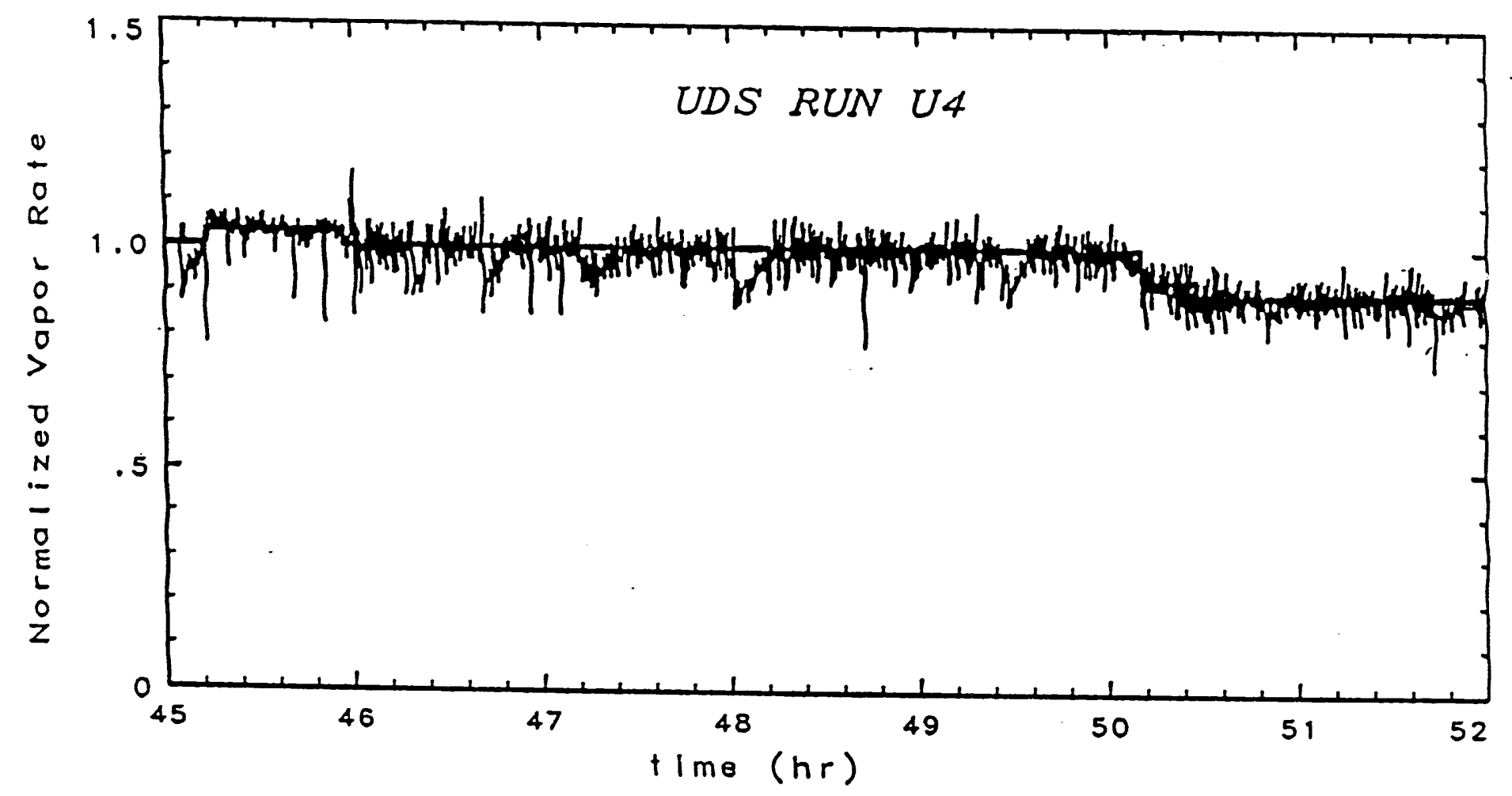

Figure 4: Vaporization rate control has been demonstrated during our plant prototypical long duration runs. Some of these runs demonstrated continuous operation for hundreds of hours. 


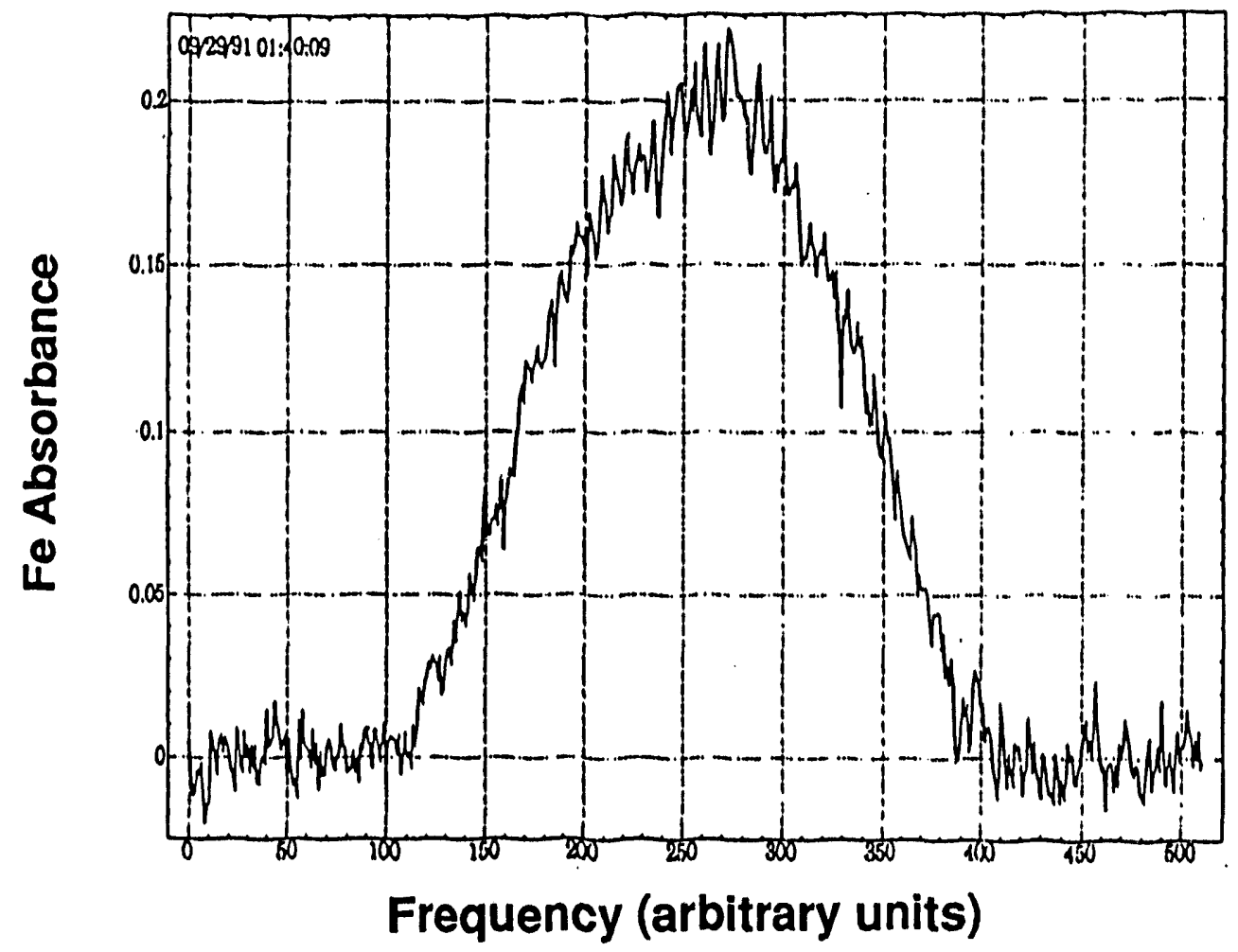

Figure 5: During steady-state operation, a symmetric absorption waveform is observed.

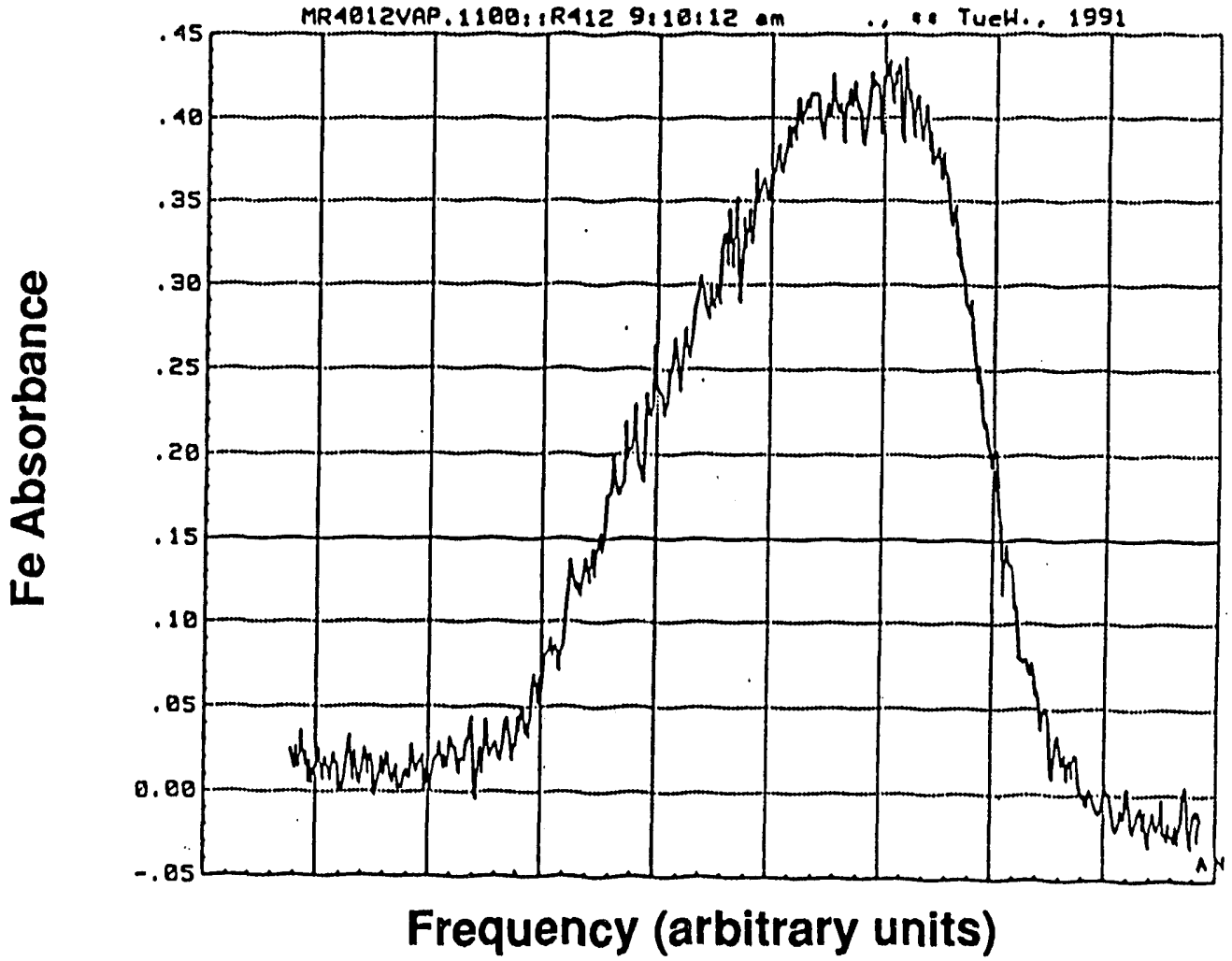

Figure 6: A non-symmetric absorption profile is observed when an excess of iron is introduced at one end of the pool. 


\section{Laser absorption spectroscopy provides a high precision vapor diagnostic}

MARTIN MARIETTA

Results of VRM system verification run

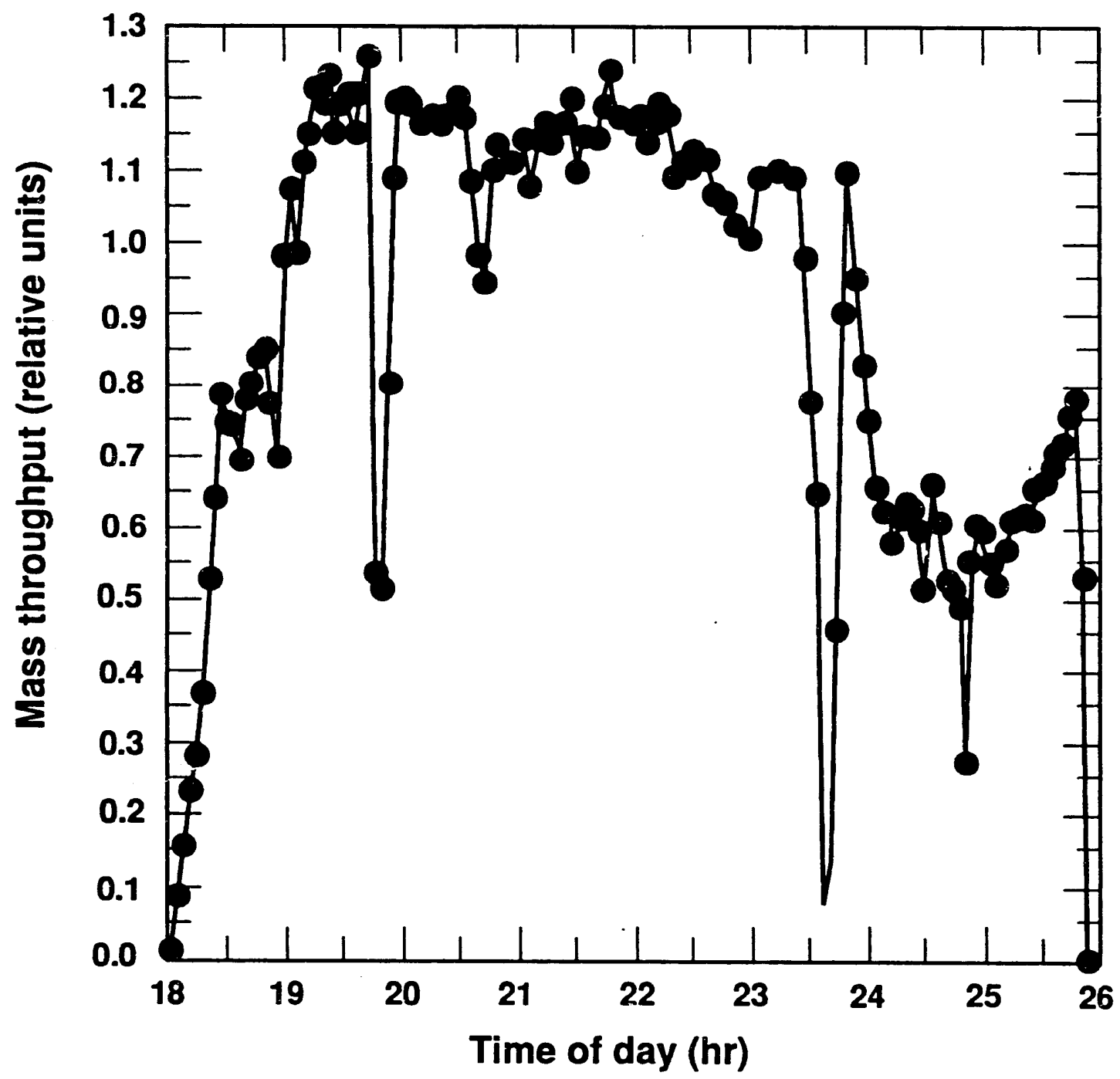

Cumulative mass:

Projected value: 721

Weighback value: 715 


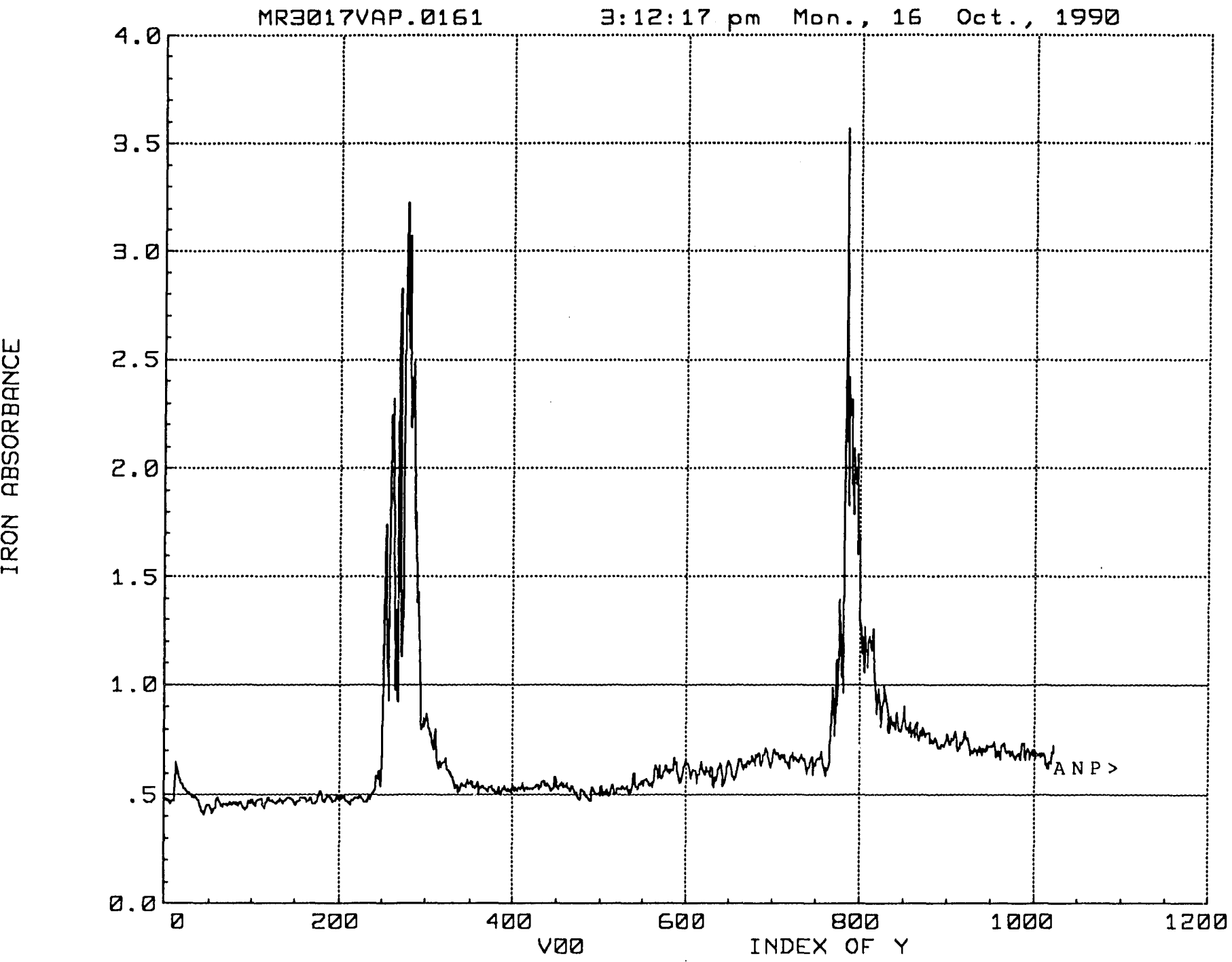

Figure 8a: Response of the iron absorbance to charges of iron fed directly to the pool. 


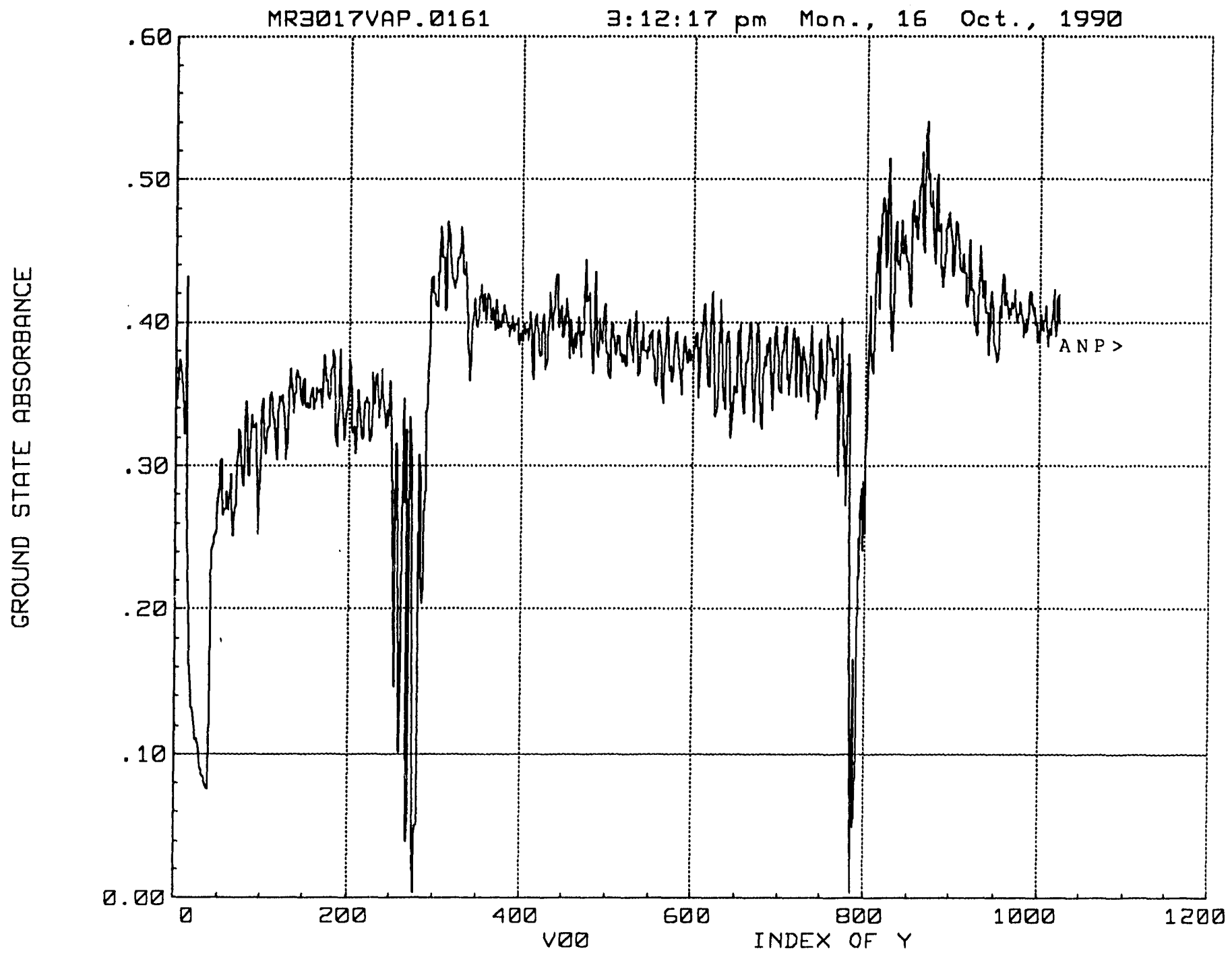

Figure 8b: Response of the uranium absorbance to charges of iron fed directly into the pool. The surplus of iron inhibits uranium vaporization. 


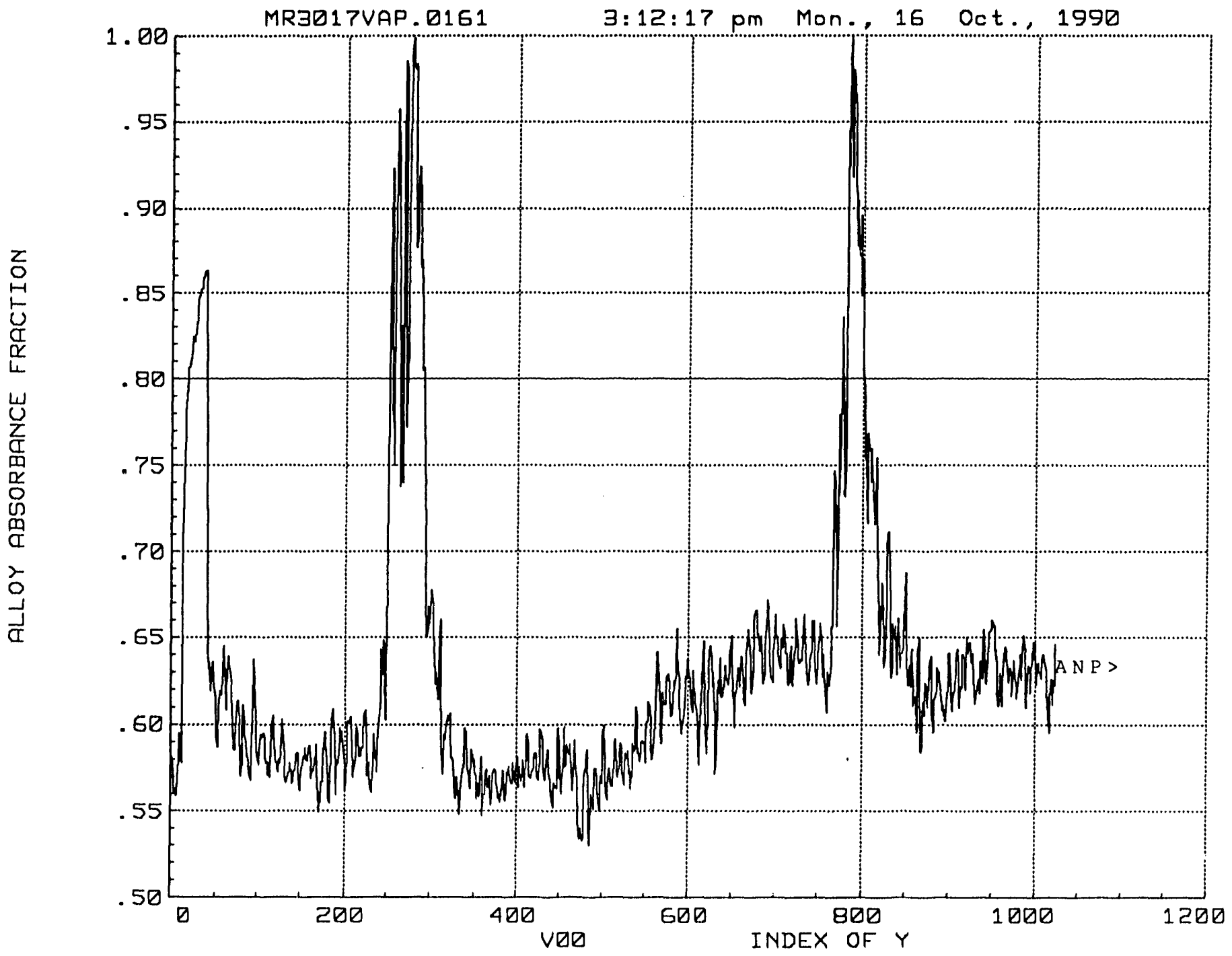

Figure 8c: The alloy absorbance fraction (a relative measure of the amount of iron in the vapor) shows that along with the instantaneous response to the iron charges, there is also a longer time scale increase in the fraction of iron in the vapor. 


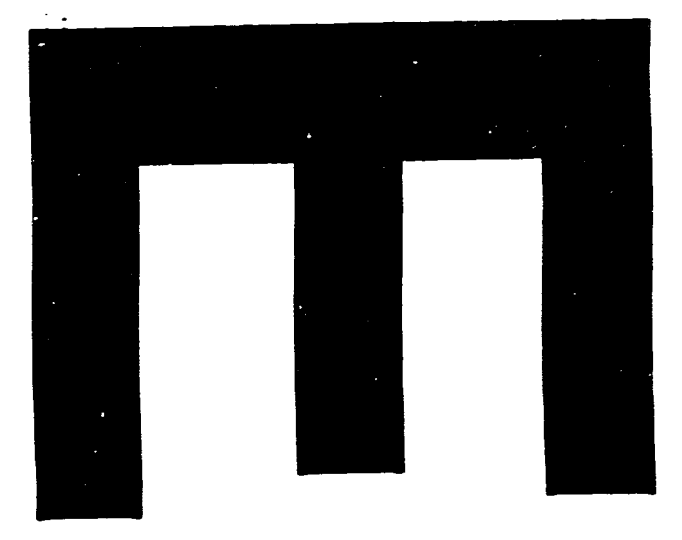

$\omega$
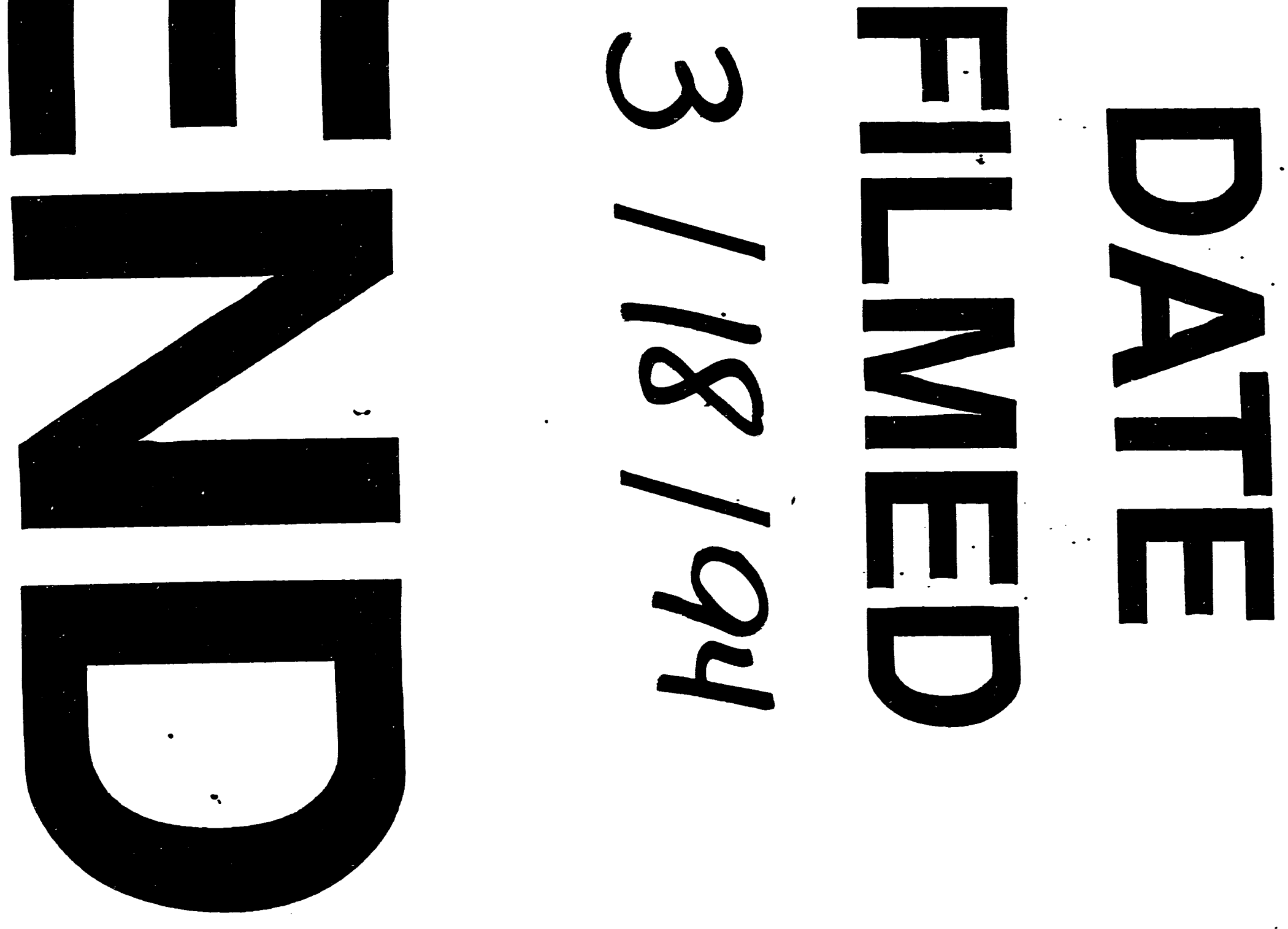
